\title{
Objects and Their Environments: From Aristotle to Ecological Ontology ${ }^{1}$
}

\author{
Barry Smith \\ Department of Philosophy, Center for Cognitive Science and National Center for \\ Geographic Information and Analysis, University at Buffalo
}

From Andrew Frank, Jonathan Raper and Jean-Paul Cheylan (eds.), The Life and Motion of SocioEconomic Units (GISDATA 8), London: Taylor and Francis, 2001, 79-97.

\section{Introduction}

What follows is a contribution to the theory of space and of spatial objects. It takes as its starting point the philosophical subfield of ontology, which can be defined as the science of what is: of the various types and categories of objects and relations in all realms of being. More specifically, it begins with ideas set forth by Aristotle in his Categories and Metaphysics, two works which constitute the first great contributions to ontological science. Because Aristotle's ontological ideas were developed prior to the scientific discoveries of the modern era, he approached the objects and relations of everyday reality with the same ontological seriousness with which scientists today approach the objects of physics. We shall seek to show that what Aristotle has to say about these commonsensical objects and relations can, when translated into more formal terms, be of use also to contemporary ontologists. More precisely, we shall argue that his ideas can contribute to the development of a rigorous theory of those social and institutional components of everyday reality - the settings of human behavior - which are the subject of this volume.

When modern-day philosophers turn their attentions to ontology they begin not with Aristotle but rather, in almost every case, with a set-theoretic ontology of the sort which is employed in standard model-theoretic semantics. Set-theoretic ontology sees the world in atomistic terms: it postulates a lowest level of atoms or urelements, from out of which successively higher levels of set-theoretic objects are then constructed. The approach to ontology to be defended here, in contrast, starts not with atoms but with the mesoscopic objects by which we are surrounded in our normal day-to-day

\footnotetext{
${ }^{1}$ My thanks go to the NCGIA (Buffalo) for helpful support, and to Andrew Frank and Dan Montello for helpful comments.
} 
activities. It sees the world not as being made up of concrete individual atoms, on the one hand, and abstract (1- and n-place) 'properties' or 'attributes', on the other. Rather, the world is made of you and me, of your headaches and my sneezes, of your battles and my wars.

The essay is divided into four main parts: the first sketches the bare bones of Aristotle's own ontology, an ontology of substances (objects, things, persons), on the one hand, and accidents (events, qualities, actions) on the other. Part 2 is a more technical section devoted to the semi-formal divisions of some of the concepts at the heart of Aristotle's theory. ${ }^{2}$ Part 3 extends the ontology to the realm of what is extended in space, and includes in particular a sketch of Aristotle's own theory of places, and the fourth and final part goes beyond Aristotle to give an account of the ontology of the environments which constitute the everyday world of human action.

\section{The Aristotelian Ontology of Substance and Accident}

\subsection{Substances}

At the heart of Aristotle's ontology is a theory of substances (things, or bodies) and accidents (qualities, events, processes). As examples of substances Aristotle has in mind primarily organisms, including human beings. But the category of substance as here conceived will embrace also such ordinary (detached, movable) objects as logs of wood, rocks, potatoes, forks. Examples of accidents are: whistles, blushes, speakings, runnings, my knowledge of French, the warmth of this stone.

To repeat, persons, too, are substances. Indeed, one important reason for admitting substances into our general ontology of everyday reality turns on the fact that we ourselves are members of this category. The ontological marks of substances, as Aristotle conceives them, are as follows: ${ }^{3}$

(i) Substances are that which can exist on their own, where accidents (processes, events, qualities, conditions) require a support from substances in order to exist. Substances are the bearers or carriers of accidents.

(ii) Substances are that which, while remaining numerically one and the same, can admit contrary accidents at different times: I am sometimes hungry, sometimes not; sometimes tanned, sometimes not.

(iii) Substances are 'one by a process of nature.' A substance has the unity of a living thing. Thus a substance enjoys a certain natural completeness or rounded-offness, being neither too small nor too

\footnotetext{
${ }^{2}$ These technical details, which are inspired in turn by Husserl 1970, are set out more thoroughly in Smith 1997, which also deals with one further major component of Aristotle's ontology, his theory of universals or categories.
}

${ }^{3}$ For further details and references to the relevant passages in Aristotle’s writings see Smith 1997. 
large - in contrast to the undetached parts of substances (my arms, my legs) and to heaps or aggregates, to complexes or collectives of substances such as armies or football teams.

(iv) A substance has a complete, determinate boundary (the latter is a special sort of part of the substance; something like a maximally thin extremal or peripheral slice).

(v) A substance has no proper parts which are themselves substances. A proper part of a substance, for as long as it remains a part, is not itself a substance; it can become a substance only if it is somehow isolated from its circumcluding whole.

(vi) A substance is similarly not the proper part of any larger substance. A substance is distinct in its form or category from any heap or aggregate or collective or complexes of substances. A substance is accordingly never scattered through space; it is always spatially connected (though it may have holes).

(vii) A substance takes up space. It is an 'extended spatial magnitude’ which occupies a place and is such as to have spatial parts. It is not merely spatially extended, but also (unlike other spatially extended objects such as places and spatial regions) such as to have divisible bulk, which means that it can in principle be divided into separate spatially extended substances.

(viii) A substance is self-identical from the beginning to the end of its existence. John as child is identical to John as adult, even though he has of course changed in many ways in the intervening years. Qualitative change is in this sense compatible with numerical identity. Thus a substance has no temporal parts: the first ten years of my life are a part of my life and not a part of me. It is not substances but accidents that can have temporal parts. The parts of an accident include its successive phases. The parts of a substance, in contrast, are its arms and legs, organs and cells, etc. (These, for as long as they are not detached, are not themselves substances.)

(ix) The existence of a substance is continuous through time: substances never enjoy intermittent existence.

It is (viii) which causes problems for standard modern approaches to ontology based on physics. This is because a substance, such as Elvis Presley, may continue to exist even though there is no physical part which survives identically from the beginning to the end of his existence. The Aristotelian ontology thus forces us to see the physical world in a new way (in terms of demarcations skew to those which are at work when we view reality through the science of physics). 


\subsection{Collectives of Substances}

A substance is never the proper part of any larger substance, but substances are often joined together into more or less complex collectives, ranging from families and tribes to nations and empires. Collectives are real constituents of the furniture of the world, but they are not additional constituents, over and above the substances which are their parts.

Collectives inherit some, but not all, of the ontological marks of substances. They can admit contrary accidents at different times, They may have a unity which is something like the unity of a living thing. They take up space, and they can in principle be divided into separate spatially extended sub-collectives, as an orchestra, for example, may be divided into constituent chamber groups. While collectives, too, are self-identical from the beginning to the end of their existence, this existence may be intermittent (as a watch, for example, may be disassembled for a time). There are no punctually existing collectives, and collectives have no temporal parts.

Most important for our purposes is the fact that collectives may gain and lose members, and they may undergo other sorts of changes through time. The Polish nobility has existed for many centuries and it will continue to exist for some time in the future.

\subsection{Accidents}

The category of substance is most intimately associated with the category of accidents. Examples of accidents include: individual qualities, actions and passions, Martha Nussbaum's present knowledge of Greek, a bruise, a handshake, an electric or magnetic charge. Accidents comprehend what, in modern parlance, are sometimes referred to as 'events', 'processes' and 'states'. Accidents are said to 'inhere' in their substances, a notion which will be defined more precisely in what follows in terms of the concept of specific dependence.

In contrast to Aristotle (and to the majority of scholastic philosophers up to and including Leibniz) we shall here embrace a view according to which accidents may be either relational or nonrelational. Non-relational accidents are attached, as it were, to a single carrier, as a thought is attached to a thinker. Accidents are relational if they depend upon a plurality of substances and thereby join the latter together into complex wholes of greater or lesser duration. Examples of relational accidents include a kiss, a hit, a dance, a conversation, a contract, a battle, a war.

Relational accidents are to be distinguished from comparatives (is longer than, is to the east of, is more famous in South Africa than) and from what are sometimes called 'Cambridge relations' (is father of, is third cousin to) (Mulligan and Smith 1986). Briefly, relational accidents are entities in their own right, with qualities and changes of their own. Comparatives and Cambridge relations, in 
contrast, if they can be said to exist at all, exist not as something extra, but only in reflection of certain special sorts of demarcation which are imposed upon the underlying bearers or upon their nonrelational accidents.

A somewhat different sort of case is illustrated by those accidents of collective wholes which may survive replacement of their bearers. We shall call objects of this sort 'instituted accidents.' Languages, religions, legal systems do not depend for their existence upon specific individuals or groups; rather, they depend generically on the existence of individuals or groups fulfilling certain necessary roles.

\subsection{Transcategorial Wholes}

Accidents, too, may form collectives, both via simultaneous compounding, as for example in the case of a musical chord or a pattern of color, and via sequencing in time, as in the case of a melody or film performance. Some collectives of accidents (for example a solo whistling of Brahms' 3rd Symphony) are accidents of substances, some (for example a stage performance of a Wagner opera) are accidents of collectives of substances. The performance of an opera is an immensely complex sequence of complex relational accidents inhering inter alia in the singers and members of the orchestra as well as in the stage and its props. Many of the most impressive achievements of human creativity consist in finding ways in which simple accidents can become compounded together to form complex accidents which are then more than (or different from) the sums of their simple parts. Complex accidents such as opera performances enjoy a complexity which embraces constituents drawn from widely diverse material domains. Already an act of promising manifests a complexity of this sort, embracing constituents of a linguistic, psychological and quasi-ethical sort, as well as physical constituents of different types (including vibrations in the air and ear and associated electrical and chemical events in the brain).

The Aristotelian distinguishes substances and accidents as two distinct orders of being. The former endure self-identically through time; the latter occur: they unfold themselves through time, and are never present in full at any given instant during which they exist. What, however, is to be said about a complex whole such as Poland, or the First World War, or the institution of the British monarchy? Each of these objects seems to involve both substances and accidents as parts. Wholes of this sort, which embrace within themselves objects from distinct ontological categories, we shall call 'transcategorial'. They are such as to cross the boundary between the two orders of (substantial and accidental) being distinguished by Aristotle, and perhaps for this reason they have been neglected in the tradition of ontology. 
Note that many transcategorial wholes in the social and institutional realm, including towns, cities, universities and corporate bodies of other types, are like instituted accidents in manifesting the ability to sustain themselves even though they are subject to a turnover of their constituent substances over time: thus they can continue to exist, even though some of their participant substances are removed and others take their place.

\section{A Theory of Objects}

\subsection{Specific Dependence}

The term 'object' in what follows will be used with absolute generality to embrace all substances, accidents, and all wholes and parts thereof, including boundaries. Our basic ontological categories will be defined in terms of the two primitive notions: is part of and is necessarily such that. ' $\mathrm{x}$ is part of $\mathrm{y}$ ' is to be understood as including the limit case where $\mathrm{x}$ and $\mathrm{y}$ are identical. The mereological notions of discreteness, overlapping and proper parthood are defined in the usual way. Thus to say that $\mathrm{x}$ is discrete from $\mathrm{y}$ is to say that $\mathrm{x}$ and $\mathrm{y}$ have no parts in common.

As we have seen, substances and accidents may be compounded together mereologically to form larger wholes of different sorts. But substances and accidents are not themselves related mereologically: a substance is not a whole made up of accidents as parts. Rather, the two are linked together via the formal tie of specific dependence, which is defined as follows:

$\mathrm{x}$ is specifically dependent on $\mathrm{y}=\mathrm{df}$. (1) $\mathrm{x}$ is discrete from $\mathrm{y}$, and (2) $\mathrm{x}$ is necessarily such that it cannot exist unless y exists.

My headache, for example, is specifically dependent on me. An accident stands to a substance in the formal tie of one-sided specific dependence only. (Thus it is clear that I am not specifically dependent on my headache.) There are also, however, cases where objects are bound together via ties of mutual specific dependence; consider for example the relation between the north and south poles of a magnet. Equally, there are cases where an object stands in a relation of specific dependence to more than one object. Thus there are relational accidents - kisses and hits - which are dependent simultaneously on a plurality of substances.

A further formal tie, in some respects the converse of that of specific dependence, is the relation of separability. We define: 
$\mathrm{x}$ and $\mathrm{y}$ are mutually separable parts of $\mathrm{z}=\mathrm{df}$. (1) $\mathrm{x}$ and $\mathrm{y}$ are parts of $\mathrm{z},(2) \mathrm{x}$ is not necessarily such that any part of y exists and (3) y is not necessarily such that any part of $\mathrm{x}$ exists, and (4) $\mathrm{x}$ is discrete from y.

$\mathrm{z}$ is, for example, a pair of stones, and $\mathrm{x}$ and $\mathrm{y}$ the stones themselves. Separability, too, may be onesided:

$\mathrm{x}$ is a one-sidedly separable part of $\mathrm{y}=\mathrm{df}$. (1) $\mathrm{x}$ is a proper part of $\mathrm{y}$, and (2) some part of $\mathrm{y}$ discrete from $\mathrm{x}$ is specifically dependent on $\mathrm{x}$, and (3) $\mathrm{x}$ is not specifically dependent on any part of $y$ discrete from $x$.

$\mathrm{x}$ is for example a human being and $\mathrm{y}$ is the sum of $\mathrm{x}$ together with some one of $\mathrm{x}$ 's thoughts.

\subsection{On Being Substantial}

How, now, can we define the notion of substance? Substances are tight unities. They do not fall apart into so many separate pieces. Accordingly we set:

$\mathrm{x}$ and $\mathrm{y}$ form a partition of $\mathrm{z}=\mathrm{df}$. (1) $\mathrm{x}$ and $\mathrm{y}$ are parts of $\mathrm{z}$, (2) $\mathrm{x}$ and $\mathrm{y}$ are discrete from each other, and (3) no part of $\mathrm{z}$ is discrete from both $\mathrm{x}$ and $\mathrm{y}$ (with analogous definitions for $\mathrm{n}$-fold partitions for each $\mathrm{n}>2$ ).

We then set:

$\mathrm{x}$ is unitary $=\mathrm{df}$. (1) $\mathrm{x}$ has no one-sidedly separable parts, and (2) there is no partition of $\mathrm{x}$ into mutually separable parts.

All substances will turn out to be unitary in our sense. If we know that $x$ is unitary, all we can infer is that all proper parts of $\mathrm{x}$ stand in mutual dependence relations to other proper parts of $\mathrm{x}$. As a further step towards a definition of the notion of substance we note that what is unitary need not, according to this definition, be independent (or in Aristotle’s terms: ‘able to exist on its own'). Indeed we can define:

$\mathrm{x}$ is an accident $=\mathrm{df}$. (1) $\mathrm{x}$ is unitary, and (2) $\mathrm{x}$ is specifically dependent on at least one substance. 
Relational accidents, such as kisses and hits, contracts and promises, are then specifically dependent on a plurality of substances.

We define further:

$\mathrm{x}$ is substantial $=\mathrm{df}$. (1) $\mathrm{x}$ is unitary and (2) $\mathrm{x}$ is not specifically dependent on any other object.

But not everything which is substantial is thereby also a substance. For our definition of 'substantial' is satisfied also by quantitative parts of substances such as Darius's (undetached) arm. ${ }^{4}$ The latter is not a substance, though it would become a substance on becoming detached, for it then acquires its own complete and exclusive boundary. In order to arrive at a definition of substance, then, it is the notion of boundary which we shall need to take as our guiding clue (something that has not been done in standard treatments of substance in the literature of analytic metaphysics - since boundaries and the mereotopological structures that go together therewith are hard to discern when the world is viewed through set-theoretic spectacles).

\subsection{Boundary-Dependence}

To this end we introduce a new sort of dependence (first discussed by Brentano and Chisholm):

$\mathrm{x}$ is boundary-dependent on $\mathrm{y}=\mathrm{df}(1) \mathrm{x}$ is a proper part of $\mathrm{y}$, and (2) $\mathrm{x}$ is necessarily such that either $\mathrm{y}$ exists or there exists some part of y properly including $\mathrm{x}$, and (3) each part of $\mathrm{x}$ satisfies (2).

$\mathrm{x}$ is for example the surface of an apple and $\mathrm{y}$ the apple itself. Clause (2) is designed to capture the topological notion of neighborhood. Roughly, a boundary of given dimension can never exist alone but exists always only as part of some extended neighborhood of higher dimension. ${ }^{5}$ There are no points, lines or surfaces in the universe which are not the boundaries of three-dimensional material things. Boundaries are then just those objects which are boundary-dependent on some other object, and ultimately on some substance.

The relation of boundary-dependence holds both between a boundary and the substance which it bounds and also among boundaries themselves. Thus zero-dimensional spatial boundaries (points) are

\footnotetext{
${ }^{4}$ That the latter is unitary follows from the fact that any pair of mutually separable parts would have to share a common boundary, which is in our terms a part, and thus would not be discrete in the sense required by the definition of mutual separability.
}

${ }^{5}$ See Varzi 1994 and Smith 1996 for details of a formal theory of mereotopology on this basis. 
boundary-dependent both on one- and two-dimensional boundaries (lines and surfaces) and also on the three-dimensional substances which are their ultimate hosts. Note that the relation of boundarydependence does not hold between an accident and its substantial carrier. Certainly my current thought satisfies the condition that it cannot exist unless I or some suitably large part of me exists. And certainly each part of my current thought satisfies this condition also. But my current thought is also specifically dependent upon me, and thus, by the definition of specific dependence it is not a part of me.

\subsection{Substance Defined}

The boundary (outer surface) of a metal sphere is a part of and is boundary-dependent on the sphere itself, but not on anything exterior to the sphere. It is this which makes the sphere a substance. We can now define:

$\mathrm{x}$ is a substance $=\mathrm{df}$. (1) $\mathrm{x}$ is substantial, (2) $\mathrm{x}$ has a boundary, (3) there is no $\mathrm{y}$ that is boundarydependent on $\mathrm{x}$ and on some object that has parts discrete from $\mathrm{x}$.

Darius's undetached arm does not satisfy this definition, since the boundary between his arm and his torso is boundary-dependent on the arm and on an object (the torso) that has parts discrete from the arm. To prove that no substance has a proper part which is itself a substance - and correlatively that no aggregate of substances is itself a substance - consider the following reductio ad absurdum argument. Suppose that $\mathrm{x}$ is a proper part of $\mathrm{y}$, and that both $\mathrm{x}$ and $\mathrm{y}$ are substances. Consider, now, the boundary of the included substance $\mathrm{x}$. This boundary must, for at least some portion of its extent, lie within the interior of the including substance $y$. This portion of the boundary of $x$ then however fails to satisfy clause (3) of our definition of substance. 


\section{Joints of Reality}

\subsection{Categories Deep and Superficial}

What is substantial is always part (though not necessarily a proper part) of some substance. From this it follows that the recognition of the category of substantials in a sense adds nothing new to the totality of what exists. Rather, it reflects cuts in reality skew to those which pick out substances and accidents - and it is the latter, we suggest, which reflect the deep structures in reality. We might indeed choose to ignore what is substantial as such, and see reality as being divided into substances and accidents alone. An adequate account of substances and accidents can however be provided only on the basis of a treatment also of what we might think of as the superficial category of substantials and of the corresponding internal boundaries. For it is part and parcel of what it is to be an extended substance that each substance is marked by the possibility of partition along an indefinite number of interior lines of division. This applies, too, to that extended substance which is the planet earth.

\subsection{The Packaging of Reality}

There are, then, different sorts of parsings or articulations of reality. The first and most important type of parsing results when we follow the outer boundaries of substances, the primary joints of reality. These are boundaries in the things themselves, boundaries of a sort which would be present even in the absence of all articulating activity on our part. We have seen the need to recognize also internal boundaries of substances which yield partitions into substantials.

Unlike outer boundaries, inner boundaries need not correspond to any genuine heterogeneity (natural articulations) on the side of the bounded objects themselves. They may be purely arbitrary. Thus imagine, again, a a homogeneous metal sphere. We can speak of articulations here (for example of the sphere into hemispheres) even in the absence of any corresponding genuine inner boundaries determined either by some interior spatial discontinuity or by some qualitative heterogeneity (of material constitution, color, texture, etc.) among the relevant object-parts. Hence we might say that there are not only genuine joints in reality, but also pseudo-joints, of the sort which divide, say, the upper and lower femur as these are depicted in atlases of surgical anatomy.

Let us call inner boundaries of the first sort, for example the boundaries around my heart and lungs, bona fide inner boundaries, inner boundaries of the second sort fiat inner boundaries - a terminology that is designed to draw attention to the sense in which the latter owe their existence to acts of human decision or fiat. ${ }^{6}$ The distinction between genuine and fiat boundaries applies not solely

\footnotetext{
${ }^{6}$ See Smith 1995, and also Smith and Varzi 1997.
} 
to inner boundaries but also to objects which play some of the roles of outer boundaries, too. National borders, as well as county- and property-lines, provide examples of fiat outer boundaries in this sense, at least in those cases where, as in the case of Colorado, Wyoming or Utah, they lie skew to any qualitative differentiations or spatio-temporal discontinuities on the side of the underlying reality.

\subsection{Fiat Objects}

But now it is clear that, when once fiat outer boundaries have been recognized, then the genuine-fiat opposition can be drawn in relation to objects also (thus in relation to both substances and accidents). Examples of genuine objects are: you and me, the planet earth, the surface of the planet earth. Examples of fiat objects are: the northern and southern hemispheres, and all geographical objects demarcated in ways which do not respect qualitative differentiations or spatio-temporal discontinuities in the underlying territory - and not the least important reason for admitting fiat objects into our general ontology turns on the fact that most of us live in one (or in what turns out to be a nested hierarchy of such objects).

Dade County, Florida, the United States, the Northern Hemisphere, etc., are fiat objects of the geographical sort. Clearly geographical fiat objects will in general have boundaries which involve a combination of bona fide and fiat elements - thus the shores of the North Sea are bona fide boundaries, though it seems reasonable to conceive the object demarcated by the totality of such boundaries as a fiat object in spite of this. Fiat objects will in general owe their existence not merely to human fiat but also to associated real properties of the relevant factual material.

The recognition of fiat objects can help us to do justice also to the fact that not all objects with which we have to deal, especially in the geopolitical and legal-administrative realms, need be connected in space. Fiat articulation can create not merely fiat object parts within genuine wholes, but also fiat object wholes out of genuine parts. And then, while genuine objects are in general connected, the fiat boundaries which circumclude constituent bona fide objects in this way are often boundaries of scattered wholes. Polynesia is a geographical example of this sort; other examples might be: the constellation Orion, the solar system, the Bahamas. 


\subsection{The Aristotelian Ontology of Places}

When we attend more closely to what it means to be in Miami, or the Lincoln Bedroom, or the Tonawanda Municipal Swimming Pool, then we discover that there is an ingredient missing from the doctrine of fiat objects as, simply, two- and three-dimensional spatial regions. What is it for a substance to be (to fit snugly) in a location or context? To arrive at an answer to this question - an answer which is not entirely satisfying, but which will yet point us in the right direction in our subsequent inquiries - it will be useful to examine Aristotle's technical notion of place.

Each substance has its place, Aristotle tells us in the Physics. The place of a substance is 'neither a part nor a state of it, but is separable from it. For place is supposed to be something like a vessel'. (209b26f.) Place cannot be a type of body, however, for if it were, then two bodies would be in the same place, and this Aristotle holds to be impossible. Place has size, therefore, but not matter. It has shape or form, but it lacks divisible bulk. But what, then, is place?

We say that a thing is in the world, in the sense of in place, because it is in the air, and the air is in the world; and when we say it is in the air, we do not mean it is in every part of the air, but that it is in the air because of the surface of the air which surrounds it; for if all the air were its place, the place of a thing would not be equal to the thing - which it is supposed to be, and which the primary place in which a thing is actually is. (211a24-28)

Place contains body: The thing relates to its place in something like the way the liquid in an urn relates to the urn, or the hand relates to the glove, or a Russian doll relates to the immediately circumjacent Russian doll. A place exactly surrounds the thing, but the place does not depend specifically upon the thing, since the latter can be substituted for another, which is then said to be in the same place. A place exactly surrounds the thing, but not in the sense in which the white of an egg exactly surrounds the yoke, for the two are here such as to form a single continuous whole, and the one is in the other (the yoke is in the egg) not as a thing in its place but as a part in its whole. A place exactly surrounds the thing rather where the thing is separate from but yet in perfect contact with its surrounding body, the latter being therefore marked by a certain sort of interior perforation or hole. The external boundary of the thing then exactly coincides with the internal boundary of that which surrounds it. Thus, when a thing is in a surrounding body of air or water then 'it is primarily in the inner surface of the surrounding body.' The boundaries of the two - the outer boundary of the thing and the inner boundary of its surrounding body - exactly coincide. (211a30-33) This, then, is place, on Aristotle's view: the place of a substance is the inner boundary of the immediate surrounding or containing body. 


\subsection{Generic Dependence}

The place is separable from the substance which occupies it in the sense that it can be occupied at different times by different substances. But the place is also dependent upon the substance, in the sense that places are essentially the sorts of objects into which substances can fit. To capture the sense in which a place is dependent upon a substance, we need to introduce the notion of generic dependence, which can be defined as follows:

$\mathrm{x}$ is generically dependent on objects of sort $\mathrm{S}=\mathrm{df}$. $\mathrm{x}$ is necessarily such that it cannot exist unless some object of sort $\mathrm{S}$ exists.

To say that a place is generically dependent on a substance of a given shape and size is to say that the place cannot exist unless some appropriate occupying substance of that shape and size exists. A father is in this sense dependent upon a child; a dog owner is dependent upon a dog; a king is dependent upon subjects - but not on any specific child, dog, or subjects. For Aristotle a place exists only if there is some body which it surrounds; but the same place can surround different bodies on different occasions, as the water in the river is different from minute to minute and from day to day. A language, religion or legal system is in the same sense generically dependent on the individuals and groups who serve in their actions to instantiate the corresponding rules, beliefs and customs.

\section{Towards a Theory of Environments}

\subsection{From Substances to Their Settings}

There are a number of strange consequences of Aristotle's theory of place. For example, it follows from the theory that proper substantial parts of bodies (for example: your leg) are not, in fact, in place - but only potentially so: they will actually be in place only if they are transformed into substances in their own right. Moreover, Aristotle associates his general ontology of place with the doctrine of natural places, according to which bodies fall down to the floor when dropped because their 'earthy' nature makes them seek the ground as resting place. The importance of his general ontology of place for our purposes here turns on the fact that it points the way to a theory of environments, of the settings or niches in which substances, and especially human and non-human animals, characteristically and for the most part, exist.

Recall, first of all, that fiat boundaries, the non-physical boundaries added to the world via human behavior and cognition, may constitute unities out of, radically heterogeneous parts. Think of a performance of a Wagner opera, a British general election, a garage sale. The wholes hereby 
constituted are spatio-temporal unities even though they are marked off from the rest of reality by no autonomous physical discontinuities. Wholes of these types - which the ecological psychologist Roger Barker has called physical-behavioral units - are of inestimable importance for an understanding of human cognition and action, since almost all human behavior occurs within one (or in what turns out to be a nested hierarchy of such wholes). Indeed, we are determined through and through as human beings by such physical-behavioral units, exactly as non-human-animals are determined through and through by the ecological niches into which they have evolved.

\subsection{The Theory of Physical-Behavioral Units}

Ontologists interested in theories of categories have not, it must be noted, invested great efforts in the working out of an ontological theory of the objective environments in which we live and move. Thus we shall be heavily dependent in what follows on the work of Barker and also on the independently developed ecological psychology of J. J. Gibson. As Gibson points out:

The world can be analyzed at many levels, from atomic through terrestrial to cosmic. There is physical structure on the scale of millimicrons at one extreme and on the scale of light years at another. But surely the appropriate scale for animals is the intermediate one of millimeters to kilometers, and it is appropriate because the world and the animal are then comparable. (Gibson 1966, p. 22)

We shall be concerned, then, still more precisely with the ontology of behavioral environments at the mesoscopic level that is determined by the everyday perceptions and actions of human beings.

The mesoscopic environment, the setting of our actions and perceptions, that into which, from moment to moment, we precisely fit, is not homogeneous. It is divided on a plurality of levels into natural units which may repeat themselves (may exist in many copies), from place to place and some of which may be such as to possess definite, salient boundaries of different sorts. Thus the mesoscopic environment is marked by the presence of substances of different sorts (buildings, rooms, walls, bricks, tables) standing in stable relations to each other. But this environment is marked also by the no less overwhelming presence of what Barker calls physical-behavioral units, recurrent types of settings, which serve as the environments for the everyday activities of persons and groups of persons. Examples are: my Friday afternoon class, Jim’s meeting with the Dean, your Thursday lunch, the plumber's visit, Gloria's drive to work. Each of these is marked by certain stable arrays of physical objects and physical infrastructure, and by certain stable patterns of behavior on the part of the persons 
involved. Physica-behavioral units are in this sense two-sided. They are built out of both physical and behavioral parts.

As Barker puts it, physical-behavioral units - conversations, speeches, hunt meets, weddings

are common phenomenal entities, and they are natural units in no way imposed by an investigator. To laymen they are as objective as rivers and forests - they are parts of the objective environment that are experienced directly as rain and sandy beaches are experienced. (Barker 1968, p. 11)

This importance of physical-behavioral units, recognized by Barker in the early 1960s, can hardly be overestimated. Even our daily ablutions, our journeys from site to site, and our loungings in daydream mode between quests, are recognizable as physical-behavioral units in Barker's terms. Even our more or less unsuccessful attempts to engage in given activities can be understand for what they are only in terms of a physical-behavioral unit of the corresponding, full-fledged type in relation to which attempt is determined as attempt and success is distinguished from failure. Only in moments of disorientation do we seem to be set free of all behavior settings, but this is just to imply that it is in relation to settings that we are in normal cases oriented.

Yet leaving aside the work of a small number of psychologists - Barker and Gibson above all, Kurt Lewin, Egon Brunswik and Fritz Heider and the Berlin Gestaltists to some degree investigations of physical-behavioral units whether by scientists or by philosophers are almost unknown. Variants of the Gestaltist concept have, it is true, been rediscovered in recent years, under different guises, by linguists such as Fillmore (1975) with his work on scenes, scripts, frames and slots. The idea is detectable also in Talmy’s work (forthcoming) on the windowing of attention in language and in Langacker's discussion (1987) of 'settings' and 'regions." As Talmy puts it:

Linguistic forms can direct the distribution of one's attention over a referent scene in a certain type of pattern, the placement of one or more windows of greatest attention over the scene, in a process that can be termed the windowing of attention. (1996, p. 236)

\footnotetext{
${ }^{7}$ See also Schank and Abelson 1977. Schoggen 1989 (pp. 302ff.) surveys a series of other near relatives of Barker's concept of physical-behavioral unit or setting, including the concept of 'domain' developed by the geographer Torsten Hagerstrand (1978).
} 
Common to all such processes is the determination of a boundary, which might be a sharp line or a gradient zone, and whose particular scope and contour - hence, the particular quantity and portions of material that it encloses - can be seen to vary from context to context. The characteristics of such boundaries include:

First ... the material enclosed within the boundary is felt to constitute a unitary coherent conceptual entity distinct from the material outside the boundary. Second, there seems to be some sense of connectivity throughout the material enclosed within the boundary and, contrariwise, some sense of discontinuity or disjuncture across the boundary between the enclosed and external material. ... Third, the various portions of the material within the boundary are felt to be corelevant to each other, whereas the material outside the boundary is not relevant to that within. (1996., p. 240)

None of these thinkers, however, has demonstrated Barker's ontological sophistication in providing an account of scenes, frames or regions as parts of reality comprehending not only human behavioral aspects but also substances and accidents belonging to the physical realm. Husserl's theory of the 'surrounding world' or 'life world' (1970a, pp. 103ff., 272) is a first, informal approximation to a ontological theory of the requisite sort. Its central idea, that an environment is that into which an organism exactly fits, is present in germ in Aristotle's doctrine of place. Physical-behavioral units (settings, scenes) have however been otherwise almost entirely neglected by philosophers. This is due, first of all, to a tendency amongst philosophers to embrace one or other form of ontological monism, a tendency which has made them glide unknowingly over objects of a transcategorial character, or seek to reduce them - for example in guise of the Wittgensteinian doctrine of 'language games', to objects of a suitably monistic flavor. It is due, secondly, to the fact that behavioral settings manifest a mereotopological character, which is, again, alien to the world view especially of contemporary philosophers, who have been inspired above all by ideas of logical construction (or more generally by ideas based on predicate logic and set theory as instruments of ontology). The formal ontology of settings, niches, or physical behavioral units is thus far completely undeveloped, in spite of the degree to which recent work in analytic metaphysics has been marked by an increasing readiness to admit into its categorial systems objects - such as artifacts, actual and possible worlds, moments, tropes and individualized properties - of non-traditional sorts. 


\subsection{Ontological Properties of Physical-Behavioral Units}

Each physical-behavioral unit has two sorts of components: human beings behaving in certain ways (lecturing, sitting, listening, eating), and non-psychological objects with which behavior is transacted (chairs, walls, paper, forks, electricity, etc.). Each physical-behavioral unit has a salient boundary which separates an organized internal (foreground) pattern from a differing external (background) pattern. This boundary, too, though it is far from simple, is an objective part of nature, though it may change according to the participants involved or according to the nature of the activity. Each unit is circumjacent to its components: the former exactly surrounds (encloses, encompasses) the latter without a break: the pupils and equipment are in the class; the shop opens at 8 a.m. and closes at 6 p.m.

A physical-behavioral unit is a unit: its parts are unified together, not through any similarity, but rather through interdependence, including that sort of interdependence which flows from the exercise of controlling power. Events within the unit have a greater effect upon each other than do equivalent events beyond its boundary.

The units have an internal structure, and individuals and categories of individuals occupy the various parts or roles within these structures to different degrees. The relation between participant and setting is to different degrees one of reciprocal co-determination. Each participant has two positions within the unit: first, he is a component which thus goes to form the unit; second, he is an individual whose behavior, and whose very nature, is itself partly formed by the unit of which he is at any given moment a part.

On the one hand is the objective environment in which we live and move. On the other hand is the interior of the organism. At the interface of these is the person, with his behavior as a person, behavior that is connected in complex ways with both his inside parts (neurons, muscles, hormones) and with the outside environment. Environment, person and bodily interior are thus combined together topologically in a nesting arrangement, so that the person, too, is in some sense a boundary or separation phenomenon within a nesting arrangement. The person, with its states and behavior (perceptions, actions, desires, beliefs, judgments, skills) stands between phenomena on its outside and on its inside, and the latter belong to different orders of reality from both the person itself and from each other. As boundary phenomenon the person is then dependent upon these two environments, the inner and outer. In particular, the person is colored and shaped, is determined through and through, by the behavioral context of the moment. And because this context is subject to constant change, then it follows, as Schoggen puts it, 
a person has many strengths, many intelligences, many social maturities, many speeds, many degrees of liberality and conservativeness, and many moralities, depending in large part on the particular contexts of the person's behavior. For example, the same person who displays marked obtusiveness when confronted with a mechanical problem may show impressive skill and adroitness in dealing with social situations. (1989, p. 7. Cf. Barker 1968, pp. 6, 161.)

\subsection{Spatial Shadows of Physical-Behavioral Units}

Each physical-behavioral unit occupies a determinate, bounded locale having observable geographical, physical and temporal attributes and having boundaries which are coincident with the boundaries of the behavior which takes place within it. Certain physical-behavioral units may in addition cast spatial shadows which endure through time. The resulting spatial projections of physicalbehavioral units are then on the one hand the product of the behavior taking place inside them; on the other hand however this behavior may itself be determined and constrained by the given spatial locale - as a football game is determined and constrained by the field on which it is played. Standing patterns of behavior are here projected in enduring fashion onto two-dimensional space (onto the surface of the earth). Enduring locales may in other cases however enjoy some of the properties of integrated physical objects, as in the case of schools and monasteries, observatories and shipyards.

In addition to such immediate spatial projections of human activity on a local scale, however, there are also varieties of human activity which cast spatial shadows in indirect fashion out into regions beyond the immediate locus of the behavior in question. This occurs for example in the case of postal districts, land-parcels within property sub-divisions, city blocks, protected wilderness zones which are the products of more or less artificial demarcations imposed on the land from without. In certain circumstances such spatial locales may take on a life of their own - they may acquire proper names, serve as the objects of emotional attachments, grow and shrink or merge and split or indeed (as in the case of Poland and Israel) survive periods of annihilation and transpositions in spatial location over time. Such objects are not behavior-settings in Barker's sense, though behavior-settings are nested within them, and these may share common characteristics in virtue of this nesting. ${ }^{8}$

${ }^{8}$ Consider Husserl's discussion of the marks of 'Europe' or of 'Western civilization' in his 1970a, pp. $269 f f$. 


\subsection{Laws of Physical-Behavioral Units}

Units have their own behavior, and their own laws which govern this behavior - laws which are different from those that govern the behavior of the person or persons involved (this, too, is a consequence of transcategoriality, and has done much to make physical-behavioral units resistant to scientific treatment). For Barker the laws governing such units may best be understood in mechanical or at least artefactual terms:

The model of an engine seems to be more appropriate to represent what occurs than is the model of an organism or person. For example, this entity can be 'turned off' and disassembled at the will of the operator, the chairman. He can adjourn the meeting (for a coffee break) and call it to order again. While it is disassembled, some of the parts can be adjusted (a discussant replaced). Individuals have no psychological properties like these. (Barker 1978, pp. 34f)

The temporal histories of at least many of the physical-behavioral units by which our lives are structured thus have shapes distinct from the temporal histories of individual persons and their individual experiences. Many physical-behavioral units have sharp beginnings and endings (consider the beginning and ending of a race, or of a contractual agreement). Our pains, illnesses, regrets, in contrast, characteristically grow and fade in intensity. Physical-behavioral units are also sometimes marked by spatial borders which are more crisp and more often rectilinear than are the spatial borders of naturally occurring phenomena such as epidemics or storms. The borders of physical-behavioral units need not be crisp in other respects, however. Consider, for example, the question whether the groom's sneezing is or is not part of that physical-behavioral unit which is his wedding.

On the other hand, physical-behavioral units manifest a capacity for self-sustenance which is much more like what we find in the biological realm. They are characteristically self-regulating, and are such as to guide their components to characteristic states and to maintain those states within limited ranges of values in the face of disturbances. ${ }^{9}$ Slight modifications within given dimensions of the unit can be sustained without detriment to its continued existence as a unit of this type. The total behavior of the unit - for example a lecture - cannot be greatly changed, however, without its being destroyed. The lecture must contain an introduction; there must be a speech, there must be listening and discussion. Within the meeting, there are the subparts: chairman, speaker, discussant, audience (as within the sentence there are the subparts: subject, verb, noun, rising inflection, etc.).

\footnotetext{
${ }^{9}$. Barker 1968, pp. 154f.
} 


\subsection{The Marks of Environments/Niches/Settings ${ }^{10}$}

The ontological marks of environments/niches/settings, as Aristotle might conceive them, are as follows:

(i) Environmental settings are complexes of substances and accidents which require a support from certain special sorts of 'participant' substances in order to exist.

(ii) Environmental settings are that which, while remaining numerically one and the same, can be sustained by distinct participant substances at different times: Clinton is sometimes President, sometimes not.

(iii) Environmental settings are 'one by a process of nature'. An environmental setting has the unity of a living thing. Thus it enjoys a certain natural completeness or rounded-offness, being neither too small nor too large - in contrast to the arbitrary undetached parts of environmental settings and to arbitrary heaps or aggregates of environmental settings .

(iv) An environmental setting has a complete boundary which is determinate at least in the sense that there are objects which fall clearly within it, and other objects which fall clearly outside it.

(v) An environmental setting has actual parts which are also environmental settings : the geometry lesson is a part of the total physical-behavioral setting of the school.

(vi) An environmental setting may similarly be the proper part of larger, circumcluding environmental settings . An environmental setting is however distinct in its form or category from any arbitrary heap of Environmental settings . An environmental setting may be scattered through space; it need not be spatially connected in the topological sense.

(vii) An environmental setting takes up space, it occupies a physical-temporal locale, and is such as to have spatial parts. It is spatially extended, but it is (unlike physical substances, land-masses, parcels of real estate) such as to have divisible bulk.

(viii) An environmental setting has a beginning and an end in time, but the environmental setting is not self-identical from the beginning to the end of its existence. John as child is identical to John as adult, but the first half of John's geometry lesson is not identical to the second half. Environmental settings , unlike substances, have temporal parts, both natural temporal parts (such as the first set of the match) and arbitrary temporal parts (such as the first 10 seconds of the geometry lesson). Environmental settings are in this respect comparable, ontologically, to accidents rather than to substances.

\footnotetext{
${ }^{10}$ For further details see Smith (forthcoming). For a formal ontology of the niche concept see Smith and Varzi 1998.
} 
(ix) The existence of an environmental setting through time need not be continuous: some environmental settings (for example a chess game, a football tournament) enjoy intermittent existence.

(x) There are no punctually existing environments, as there are punctual events (for example beginnings, endings, and instantaneous changes of other sorts).

\subsection{Hierarchical Nesting}

Many ecological units occur in assemblies, as a chick embryo, for example, is constructed as a nested hierarchy of organs, cells, nuclei, molecules, atoms, and subatomic particles.

A unit in the middle range of a nesting structure is simultaneously both circumjacent and interjacent, both whole and part, both entity and environment. An organ -the liver, for example - is whole in relation to its own component pattern of cells, and is a part in relation to the circumjacent organism that it, with other organs, composes; it forms the environment of its cells, and is, itself, environed by the organism. (Barker 1968, p. 154)

Physical-behavioral units, too, may be nested together in hierarchies in this way. There are typically many units of each lower-level kind within a given locality, and these are typically embedded within larger units: the game is embedded within the match, the honeymoon is embedded within the marriage, the lecture meeting is embedded within the university. The drawing of the triangle on the blackboard is embedded within the geometry lesson, which is embedded within the school, which is embedded within the city. Each of these are physical-behavioral units in Barker's sense. On the other hand, a randomly delineated square mile in the center of a city is not a physical-behavioral unit, nor is the mereological sum of its Republican voters; the former has no self-generated unity; the latter has no continuously bounded space-time locus. ${ }^{11}$

\footnotetext{
${ }^{11}$. Cf. Barker 1968, pp. 11f., 16; 1978, p. 34.
} 


\subsection{The Systematic Mutual Fittingness of Behavior and Ecological Setting}

The behavior and the physical objects that together constitute the totality of a given physicalbehavioral unit are intertwined in such a way as to form a pattern that is by no means random: there is a relation of harmonious fit between the standard patterns of behavior occurring within the unit and the pattern of its physical components. (The seats in the lecture hall are such as to face the speaker. The speaker addresses his remarks out towards the audience. The boundary of the football field is, apart from certain well-defined exceptions, the boundary of the game. The beginning and end of the school music period mark the limits of the pattern of music behavior.) This mutual fittingness of behavior and physical environment extends to the fine, interior structure of a behavior in a way which will imply a radical nontransposability of standing patterns of behavior from one environment to another. The conditions obtaining in particular settings are as essential for some kinds of behavior as are persons with the requisite motives and skills. ${ }^{12}$

There are various forces or influences which help to bring about and to sustain this mutual fittingness. ${ }^{13}$ Forces which flow in the direction from setting to behavior include physical constraints exercised by hedges, walls or corridors or by persons with sticks; they include social forces manifested in the authority of the teacher, in threats, promises, warnings; they include the physiological effects of climate, the need for food and water; and they include the effects of perceived physiognomic features of the environment (open spaces seduce children, a businesslike atmosphere encourages businesslike behavior). Mutual fittingness can be reinforced by learning, and also by a process of selection of the persons involved, whether this be one of self-selection (of children who remain in Sunday school class in light of their ability to conform to the corresponding standing patterns of behavior), or a matter of externally imposed entrance tests. Forces which flow in the contrary direction, which is to say from behavior to setting, include all those ways in which a succession of separate and uncoordinated actions can have unintended consequences in the form of new types of actions and new, modified types of settings in the future (as the passage of many feet causes pathways to form in the hillside).

\footnotetext{
${ }^{12}$. Barker 1968, pp. 32.

${ }^{13}$. Cf. Barker 1968, pp. 30f. Schoggen (1989, p. 4) describes physical-behavioral settings as consisting of 'highly structured, improbable arrangements of objects and events that coerce behavior in accordance with their own dynamic patterning.'
} 


\subsection{Ontological Transcategoriality of Ecological Settings}

A physical-behavioral unit such as a religious meeting, a tennis championship or a sea battle is an intricate complex of times, places, actions, and things. Its constituents can include both manmade elements (buildings, streets, cricket pitches, books, pianos, libraries, the bridges and engine-rooms of battleships) and also natural features (hills, lakes, waves, particular climatic features, patterns of light and sound). These features and elements may be further restricted to a highly specific combination of, say, a particular room in a particular building at a particular time with particular persons and objects distributed in a particular pattern. But the total unit may comprehend also a variety of non-physical components in addition to the behavior of the persons involved. Thus the unit may comprehend for example different types of linguistic, legal and institutional elements, all combined together in space and time in highly specific ways. The phenomena involved are in addition diverse not only as concerns their material constitution but also as concerns their ontological form (thus they comprehend substances, events, actions, states and manifold relations between all of these). As Barker puts it:

The conceptual incommensurability of phenomena which is such an obstacle to the unification of the sciences does not appear to trouble nature's units. - Within the larger units, things and events from conceptually more and more alien sciences are incorporated and regulated. (1968, p. 155)

As far as our behavior is concerned, therefore, even the most radical diversity of kinds and categories need not prevent integration.

Hand in hand with the ontological transcategoriality of behavior settings goes also the ontological transcategoriality of the associated boundaries. Physical-behavioral units are set apart from each other, and from the surrounding environment, not only via boundaries of a simple spatial and temporal sort. There are boundaries also of granularity: some events, for example events on a molecular scale, are standardly of too small a scale to function as events (to be salient features of) physical-behavioral units of the types we are here considering. Events within the interior of my body, too, are standardly such as to fall outside the boundary of the physical-behavioral units in which we standardly engage (not, however, outside the boundary of neurologists or gastroenterologists). Only some sorts of noises will be such as to fall within the boundary of a symphony concert. Only some sorts of deaths will be such as to fall within the boundary of a battle or war. From the standpoint of formal ontology, too, the boundaries of physical-behavioral settings are transcategorial. Thus the boundary of a horse-race comprehends within its scope certain substances (horses, riders, spectators), a certain region of space and associated fixtures (land, fences, starting-gate, pavilion), but also certain events, processes, relations, and properties of materially determinate types. 


\subsection{The Ecological Niche}

For Gibson, too, reality is a complex hierarchy of inter-nested levels: molecules are nested within cells, cells are nested within leaves, leaves are nested within trees, trees are nested within forests, and so on (Gibson 1986, p. 101). Each type of organism is tuned in its perception and actions to objects on a specific level within this complex hierarchy, to objects which together form what Gibson calls an 'ecological niche'. (Gibson's own account of this relationship of tuning - in terms of information pick-up - need not detain us here.) A niche is that into which an animal fits; it is that in relation to which the animal is habituated in its behavior. ${ }^{14} \mathrm{~A}$ niche embraces not only objects of different sorts, but also shapes, colors, textures, tendencies, boundaries (surfaces, edges), all of which are organized in such a way as to enjoy affordance-character for the animal in question: they are relevant to its survival. The given features motivate the organism; they are such as to intrude upon its life, to stimulate the organism in a range of different ways.

The perceptions and actions of human beings are likewise tuned to the characteristic shapes and qualities and patterns of behavior of our own respective natural environments. This mutual embranglement is however in our case extended further via artefacts, and via cultural phenomena such as language and its associated institutions. To learn a language is in part also to extend the range of objects in relation to which we are able spontaneously to adjust our behavior and thus to extend radically the types of niche or setting into which we can spontaneously fit.

\subsection{In Defense of Realism}

A science of human environments will look very different from any science of the more standard sort. This has led some philosophers and cognitive scientists to suppose that environments, settings, physical-behavioral units are phenomena only - that they are subjective constructs, properly to be treated within the methodologically solipsistic framework of psychology. The challenge, then, as Gibson saw, is to demonstrate how a science of environmental settings can be 'consistent with physics, mechanics, optics, acoustics, and chemistry', being only a matter of 'facts of higher order that have never been made explicit by these sciences and have gone unrecognized.' (Gibson 1979, p. 17) Hence it should be possible to develop a realist theory of the physical-behavioral units and of other types of fiat objects relevant to everyday human cognition in a manner which does not involve the rejection of standard quantitative physics. Gibson uses the term 'ecology' precisely in order to designate the discipline that should encompass these intermediate-level facts; it is presented as 'a

\footnotetext{
${ }^{14}$ Gibson 1986, p. 129.
} 
blend of physics, geology, biology, archeology, and anthropology, but with an attempt at unification' on the basis of the question: what can stimulate the organism? (Gibson 1966, p. 21) The science of ecology will differ from these disciplines in that it will focus on cuts through reality of a different sort.

\section{References}

Barker, Roger G. 1968 Ecological Psychology. Concepts and Methods for Studying the Environment of Human Behavior, Stanford: Stanford University Press.

Barker, Roger G. and Associates 1978 Habitats, Environments, and Human Behavior. Studies in Ecological Psychology and Eco-Behavioral Science from the Midwest Psychological Field Station, 1947-1972, San Francisco: Jossey-Bass Publishers.

Brentano, Franz 1988 Philosophical Investigations on Space, Time and the Continuum, ed. by R. M. Chisholm and S. Körner, Hamburg: Meiner, Eng. trans. by B. Smith, London: Croom Helm, 1988.

Chisholm, R. M. 1984 "Boundaries as Dependent Particulars”, Grazer Philosophische Studien, 10, 87-95.

Fillmore, Charles 1975 “An Alternative to Checklist Theories of Meaning," in C. Cogen, et al., eds., Proceedings of the Berkeley Linguistics Society, Berkeley: Berkeley Linguistics Society, 123-31.

Gibson, J. J. 1966 The Senses Considered as Perceptual Systems, London: George Allen and Unwin. Gibson, J. J. 1979 The Ecological Approach to Visual Perception, Boston: Houghton-Mifflin, repr. 1986, Hillsdale, NJ: Lawrence Erlbaum.

Hagerstrand, Torsten 1978 "Survival and Arena: On the Life History of Individuals in Relation to Their Geographical Environments”, in T. Carlstein, et al., eds., Timing Space and Spacing Time, Volume 2, London: Edward Arnold, 121-45.

Heider, Fritz 1959 On Perception and Event Structure, and the Psychological Environment, Selected Papers (Psychological Issues, Vol. 1, No. 3), New York: International Universities Press.

Husserl, Edmund 1970 Logical Investigations, 2 vols., translated by J. N. Findlay, London: Routledge and Kegan Paul.

Husserl, Edmund 1970a The Crisis of European Sciences and Transcendental Phenomenology, translated by D. Carr, Evanston: Northwestern University Press.

Langacker, Ronald W. 1987 Foundations of Cognitive Grammar, vol. 1, Theoretical Prerequisites, Stanford: Stanford University Press.

Mulligan, Kevin and Smith, Barry 1986 “A Relational Theory of the Act”, Topoi, 5/2, 115-30.

Schank, R. C. and Abelson, R. P. 1977 Scripts, Plans, Goals and Understanding: An Inquiry into Human Knowledge Structures, Hillsdale, NJ: Erlbaum. 
Schoggen, P. 1989 Behavior Settings. A Revision and Extension of Roger G. Barker”s Ecological Psychology, Stanford: Stanford University Press.

Simons, Peter M. 1987 Parts. A Study in Ontology, Oxford: Clarendon Press.

Smith, Barry 1995 “On Drawing Lines on a Map”, in Andrew U. Frank und Werner Kuhn (Hrsg.), Spatial Information Theory. A Theoretical Basis for GIS (Lecture Notes in Computer Science 988), Berlin/Heidelberg/New York: Springer, 475-484.

Smith, Barry 1996 "Mereotopology: A Theory of Parts and Boundaries”, Data and Knowledge Engineering, 20, 287-303.

Smith, Barry 1997 “On Substances, Accidents and Universals: In Defence of a Constituent Ontology”, Philosophical Papers, 26, 105-127.

Smith, Barry (forthcoming) "Ontologie des Mesokosmos. Soziale Objekte und Umwelten", Zeitschrift fuer philosophische Forschung.

Smith, Barry and Varzi, Achille C. 1997 "Fiat and Bona Fide Boundaries: Towards on Ontology of Spatially Extended Objects”, COSIT '97: Conference on Spatial Information Theory (Springer Lecture Notes), Berlin/Heidelberg/New York: Springer Verlag.

Smith, Barry and Varzi, Achille C. 1998 "The Niche", Working Papers of the Center for Cognitive Science, University at Buffalo.

Talmy, Leonard 1996 "The windowing of attention in language”, in Masayoshi Shibatani and Sandra Thompson, eds., Grammatical Constructions: Their Form and Meaning, Oxford: Oxford University Press, 235-287.

Varzi, Achille C. 1994 "On the Boundary between Mereology and Topology”, in R. Casati, B. Smith and G. White (eds.), Philosophy and the Cognitive Sciences, Vienna: Hölder-Pichler-Tempsky, 423442. 